\title{
THE ACPI PROJECT, ELEMENT 1: INITIALIZING A COUPLED CLIMATE MODEL FROM OBSERVED CONDITIONS
}

\author{
DAVID W. PIERCE ${ }^{1}$, TIM P. BARNETT ${ }^{1}$, ROBIN TOKMAKIAN ${ }^{2}$, \\ ALBERT SEMTNER $^{2}$, MATHEW MALTRUD ${ }^{3}$, JOANNE LYSNE ${ }^{3}$ and \\ ANTHONY CRAIG ${ }^{4}$ \\ ${ }^{1}$ Climate Research Division 0224, Scripps Institution of Oceanography, \\ La Jolla, CA 920930224, U.S.A. \\ E-mail:dpierce@ucsd.edu \\ ${ }^{2}$ Naval Postgraduate School, Monterey, California, U.S.A. \\ ${ }^{3}$ Los Alamos National Laboratory, Los Alamos, New Mexico, U.S.A. \\ ${ }^{4}$ National Center for Atmospheric Research, Boulder, Colorado, U.S.A.
}

\begin{abstract}
A problem for climate change studies with coupled ocean-atmosphere models has been how to incorporate observed initial conditions into the ocean, which holds most of the 'memory' of anthropogenic forcing effects. The first difficulty is the lack of comprehensive three-dimensional observations of the current ocean temperature (T) and salinity (S) fields to initialize to. The second problem is that directly imposing observed $\mathrm{T}$ and $\mathrm{S}$ fields into the model results in rapid drift back to the model climatology, with the corresponding loss of the observed information. Anthropogenic forcing scenarios therefore typically initialize future runs by starting with pre-industrial conditions. However, if the future climate depends on the details of the present climate, then initializing the model to observations may provide more accurate forecasts. Also, this $\sim 130 \mathrm{yr}$ spin up imposes substantial overhead if only a few decades of predictions are desired. A new technique to address these problems is presented. In lieu of observed $\mathrm{T}$ and $\mathrm{S}$, assimilated ocean data were used. To reduce model drift, an anomaly coupling scheme was devised. This consists of letting the model's climatological (pre-industrial) oceanic and atmospheric heat contents and transports balance each other, while adding on the (much smaller) changes in heat content since the pre-industrial era as anomalies. The result is model drift of no more than $0.2 \mathrm{~K}$ over 50 years, significantly smaller than the forced response of $1.0 \mathrm{~K}$. An ensemble of runs with these assimilated initial conditions is then compared to a set spun up from pre-industrial conditions. No systematic differences were found, i.e., the model simulation of the ocean temperature structure in the late 1990s is statistically indistinguishable from the assimilated observations. However, a model with a worse representation of the late 20th century climate might show significant differences if initialized in this way.
\end{abstract}

\section{Introduction}

The overall objective of the pilot-ACPI project was a demonstration of 'end-to-end' prediction of water resources in the western U.S. over the period 1995 to 2050. This paper describes the front end of the project, namely, initializing a coupled oceanatmosphere general circulation model (O/A GCM) with observed ocean conditions. This was referred to as Element 1 in the overview paper by Barnett et al. (2004) 
in this issue. This element is important because most of the climate's 'memory' of previous anthropogenic forcing resides in the ocean, specifically in an increase in the ocean's heat content (possibly with associated changes in the circulation), since the heat capacity of the ocean is so much greater than that of the atmosphere and cryosphere (Levitus et al., 2000). Changes in glaciers might also be of practical importance for ecosystems or sea level, but since the PCM has no dynamic glacier model it is a moot point for our purposes. Therefore, initializing to the correct climate state devolves to initializing to the correct ocean state.

Our goal was to start the model runs with the best possible estimate of the ocean's state in the late twentieth century. This requirement was imposed because the warming the climate has already experienced by the year 2000 might have an influence on its later evolution. Ignoring this earlier warming is often referred to as the 'cold start' problem (Hasselmann et al., 1993; Schneider, 1996). Typically, this is addressed by using a spinup run starting in pre-industrial times. For example, the PCM historical scenarios start in 1870 (Washington et al., 2000), resulting in a climate in the 1990s that is demonstrably warmer than the 1870 s. We chose instead to initialize the coupled model to observed conditions, because if future climate depends on the details of the late 20th century climate, then accurate forecasts require accurate initial conditions. Our hypothesis is that observations provide more accurate initial conditions than a model spinup run. A secondary benefit is that no spinup run is then needed; going from 1870 to 1999 is 130 years, a large overhead when the goal is to integrate only 50 years into the future.

The first objective of this note is to describe the technique used to initialize the coupled O/A GCM with observed conditions, which does not seem to have been done previously in anthropogenic scenario predictions. The second objective is to quantitatively address whether initializing to observations results in different climate forecasts than obtained from a spin-up run. Does proper initialization make any difference to later climate?

This note is laid out as follows. The O/A GCM used for these experiments will be briefly described in Section 2. The assmiliated oceanic temperature (T) and salinity (S) fields used to initialize the model are described in Section 3. How to introduce the observed $\mathrm{T}$ and $\mathrm{S}$ fields into the coupled model without drift that would obscure the signals of interest is addressed in Section 4. Mitigating the impacts of interdecadal and interannual variability (those being not of direct interest in this project) is described in Section 5. We then evaluated whether the new initialization condition made any difference to the climate (Section 6); we found that it did not, although with some important caveats. The note concludes with a discussion of the scientific questions left unanswered by this phase of the pilot project (Section 7). 


\section{The Parallel Climate Model}

This work used the Parallel Climate Model (PCM), version 1 (Washington et al., 2000). Dai et al. (2004, this issue) describe the model in detail, so only a brief outline will be given here.

The atmospheric component is the CCM3 atmospheric general circulation model (Kiehl et al., 1998), a spectral model with T42 resolution (equivalent to about 280 by $280 \mathrm{~km}$ grid spacing), and 18 layers in the vertical using hybrid sigma coordinates. CCM3 includes a land surface model that accounts for soil moisture and vegetation types and a simplified runoff scheme.

The ocean component is the Parallel Ocean Program (POP; Smith et al., 1992; Dukowicz and Smith, 1994), with a horizontal resolution of 384 by 288 grid points (roughly $2 / 3^{\circ}$ resolution), and 32 vertical levels that are clustered near the surface to improve resolution of surface processes. A displaced-pole grid in the northern hemisphere eliminates the problem of convergence of the meridians in the Arctic Ocean.

A dynamic-thermodynamic sea-ice model based on Zhang and Hibler (1997) is included, with an elastic-viscous-plastic rheology for computational efficiency (Hunke and Dukowicz, 1997). The ice model is formulated on its own grid, which has a total of 320 by 640 gridpoints, and a physical grid spacing of roughly $27 \mathrm{~km}$.

\section{The Assimilated Ocean Data Set}

We used the output of ECCO ocean state estimation project (Stammer et al., 1997, 2002; http://www.ecco.ucsd.edu) to provide oceanic T and S in the 1990s since there are no systematic three dimensional observations available for initialization. This assimilates satellite-observed sea surface height altimetry from TOPEX/POSEIDON (Fu et al., 1994), NCEP surface forcing fields (Kalnay et al., 1996), and the three-dimensional Levitus (1994) $\mathrm{T}$ and $\mathrm{S}$ climatology fields into the MIT ocean model (Marshall et al., 1997a,b; Adcroft et al., 1997) at a $2 \times 2$ degree global resolution. The period covered is 1992 to 1997.

The assimilation technique makes use of an 'adjoint' model. In essence, the ocean assimiliation model is integrated forward as usual and discrepancies from the observations quantified. Then, an inverse (adjoint) version of the model is used to show which initial conditions or forcing fields contributed most to the errors, and the change needed to reduce the errors. The most error-generating inputs are adjusted accordingly (keeping within the limits of uncertainty to which they are known), and the process repeated. Many forward-inverse iterations are needed for the process to converge. The advantage of this technique compared to assimilation schemes based on 'nudging' is that the final result is dynamically and thermodynamically consistent at all times. Nudging schemes, by contrast, do not have closed budgets (for example, when temperatures are nudged warmer to better match ob- 
servations, there is no dynamical or thermodynamic source of this heat - it just appears). In later sections, the assimilated data will be referred to simply as the 'observed' data.

The MIT ocean model was used for the assimilation, while PCM uses the POP ocean model. These are similar in many ways (e.g., both are z-level), but have different numerical formulations. How much will the PCM ocean drift given that the initial and boundary conditions are consistent with the MIT model rather than POP?

We attempted to quantify this by running stand-alone POP simulations configured as identically as possible to the MIT model. The simulations were forced using the adjusted (daily) NCEP fluxes discussed above. After 5 years, the average SSTs from the two models differ by over $0.5 \mathrm{~K}$. In addition, the rms SST difference is $>1 \mathrm{~K}$ after 5 years. This highlights the possibility that the two models are different enough to result in some drift due simply to incompatibilities between the assimilation model and the coupled model, which should be kept in mind.

\section{Coupled Model Initialization}

Why is it hard to insert observed $\mathrm{T}$ and $\mathrm{S}$ fields into a coupled model? The problem is that this generally results in rapid drift back to the model's mean state. The inserted information is lost, and the model drift is hard to distinguish from a response to the imposed forcing.

More precisely, drift results from mismatches between the observed and modeled ocean heat content and implied heat transport. In places where the heat transports do not match, the model's temperature must adjust until they do; i.e., the temperature drifts. It is necessary to have considerably less drift than forced response if the results are to be interpreted as coming from the forcing instead of the drift.

\subsection{DIRECT INSERTION OF ASSIMILATED FIELDS}

A first test was done to see how big this drift would be. The assimilated $\mathrm{T}$ and $\mathrm{S}$ fields were directly inserted into the ocean model, and the coupled model run forward. The results of this experiment (case B06.33) for the global-average surface temperature field are shown in Figure 1 (line with solid squares). There is an initial discontinuity; thereafter, the globally averaged surface temperatures drift at a rate of $0.3 \mathrm{~K} /$ decade back down to the model climatology. This drift is twice as strong as the forced model response (line with open circles in Figure 1) obtained from runs with atmospheric $\mathrm{CO}_{2}$ concentrations increasing according to the 'business as usual' (BAU) scenario (comparable to the IPCC Scenario 'IS92a'; IPCC, 1994). Therefore, this simplistic initialization technique is not useful for our purposes, and the run was terminated after 18 years. 


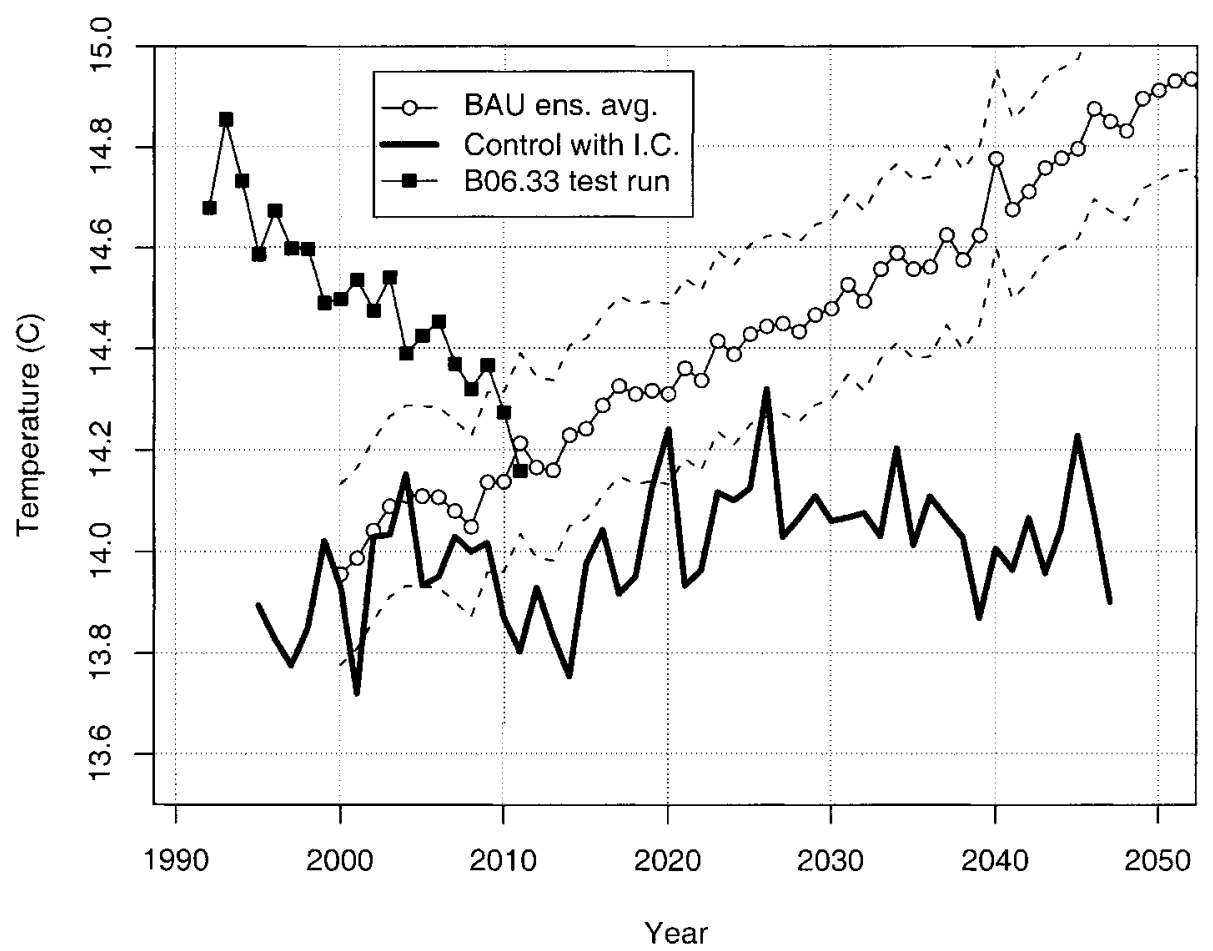

Figure 1. Global-average surface temperature (C). Light line with open circles: the ensemble average for the five BAU runs, along with $+/-2$ standard deviations of the ensemble spread (light dotted lines). Solid heavy line: the control run with assimilated initial conditions. Light line with filled squares: test case B06.33, where the ocean model was restarted with the absolute assimilated $\mathrm{T}$ and $\mathrm{S}$ fields (i.e., no anomaly coupling scheme was used).

Various flux correction schemes that would minimize the drift were considered. The philosophy of these is to put the observed ocean $\mathrm{T}$ and $\mathrm{S}$ fields directly into the coupled model (as in B06.33), then diagnose the surface heat flux mismatches (i.e., determine those places where the vertically integrated ocean and atmosphere heat transports do not match). Artificial heat sources and sinks can then be added at the ocean's surface to make the two fields balance. However, a significant drawback of such schemes is that the future evolution of the atmosphere might be affected by these fictitious heat fluxes. Therefore, another method was sought.

\subsection{THE ANOMALY COUPLING SCHEME}

To minimize the drift we used the following anomaly coupling scheme. The ocean heat content (HC) in year 1995, in both the model and observations, can be written as:

$$
\begin{aligned}
& \mathrm{HC}_{\mathrm{obs}}^{1995}=\mathrm{HC}_{\mathrm{obs}}^{1870}+\Delta \mathrm{HC}_{\mathrm{obs}} \\
& \mathrm{HC}_{\text {model }}^{1995}=\mathrm{HC}_{\text {model }}^{1870}+\Delta \mathrm{HC}_{\text {model }},
\end{aligned}
$$


where $\Delta \mathrm{HC}_{\mathrm{obs}}$ is the change in the ocean's heat content due to anthropogenic forcing, solar fluctuations, volcanic influences, and natural variability over the period 1870 to 1995 . The model value, $\Delta \mathrm{HC}_{\text {model }}$, is similar, except solar and volcanic variability are not included in the model (but see Meehl et al., 2002). The anomaly coupling method is useful because, for both the model and observations, $\mathrm{HC}^{1870} \gg \Delta \mathrm{HC}$. I.e., perturbations since 1870 are only a small part of the mean $\mathrm{HC}$ (note this might not be true in the future if anthropogenic forcing results in the collapse of the thermohaline circulation). This motivates approximating the model's heat content as:

$$
\mathrm{HC}_{\text {model }}^{1995} \approx \mathrm{HC}_{\text {model }}^{1870}+\Delta \mathrm{HC}_{\text {obs }} \text {. }
$$

This approximation may be of substantial benefit because errors in $\triangle \mathrm{HC}$ are likely to be much smaller in absolute magnitude than errors in $\mathrm{HC}^{1870}$, resulting in smaller model drift needed to correct those errors. In essence, this technique allows the large climatological heat transports from the coupled model's ocean and atmosphere to balance each other, while the small anomalous heat content changes due to anthropogenic forcing and various processes not included in the model are directly inserted from observations. Estimating the size of terms from the PCM's historical runs, and expressing them as RMS values of the surface heat flux field using the relation between surface fluxes and the vertical integral of yearly averaged ocean heat transport (OHT) from the bottom to the surface, we have $\nabla$. $\int \mathrm{OHT}^{1870} d z \sim 60-80 \mathrm{~W} \mathrm{~m}^{-2}$, while $\nabla \cdot \int \Delta \mathrm{OHT} d z \sim 2-4 \mathrm{~W} \mathrm{~m}^{-2}$. Thus, this can potentially reduce problems with surface heat flux mismatches by an order of magnitude, with a corresponding reduction in the rate of model drift.

It would be best to estimate $\Delta \mathrm{HC}_{\mathrm{obs}}$ (the change in $\mathrm{HC}$ from 1870 to 1995) from the change in the three-dimensional T field from 1870 to 1995 . However this field is not known, since the assimilation data covers only the relatively brief period 1992-1997. We make the assumption that the majority of the signal can be obtained by taking the difference between the assimilated T field averaged over 1995-1997 and the Levitus (1994) climatological T field. Part of the motivation for this is that the assimilation procedure starts with the Levitus field at the beginning of the run, before incorporating recent observations; thus, the assimilation procedure results in forced departures from Levitus climatology.

This assumption may introduce errors to the extent that the Levitus climatology does not represent the state of the ocean in 1870. Natural variability is always occurring, and may bias the estimation in places. Also, the actual time that the Levitus climatology represents is uncertain, and perhaps ill-defined given the continuously increasing anthropogenic forcing over the modern time period. Figure 2 shows the fraction of ocean volume (to $3000 \mathrm{~m}$ ) reported as sampled by the Levitus pentadal averages as a function of time; a simple weighted average of the data suggests an average time around 1970. In lieu of direct oceanic measurements, we estimate the amount of ocean heating from 1870 to 1970 from the record of global surface temperatures (Figure 3; Jones et al., 1999). These show that about 1/3 of 


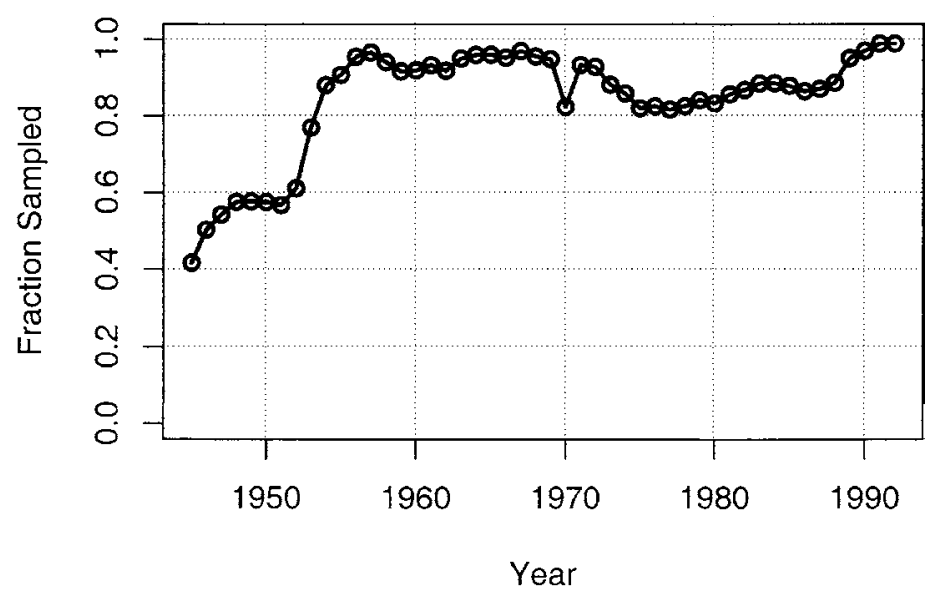

Figure 2. Fraction of the world ocean volume to $3000 \mathrm{~m}$ sampled by the Levitus data set, as a function of time.

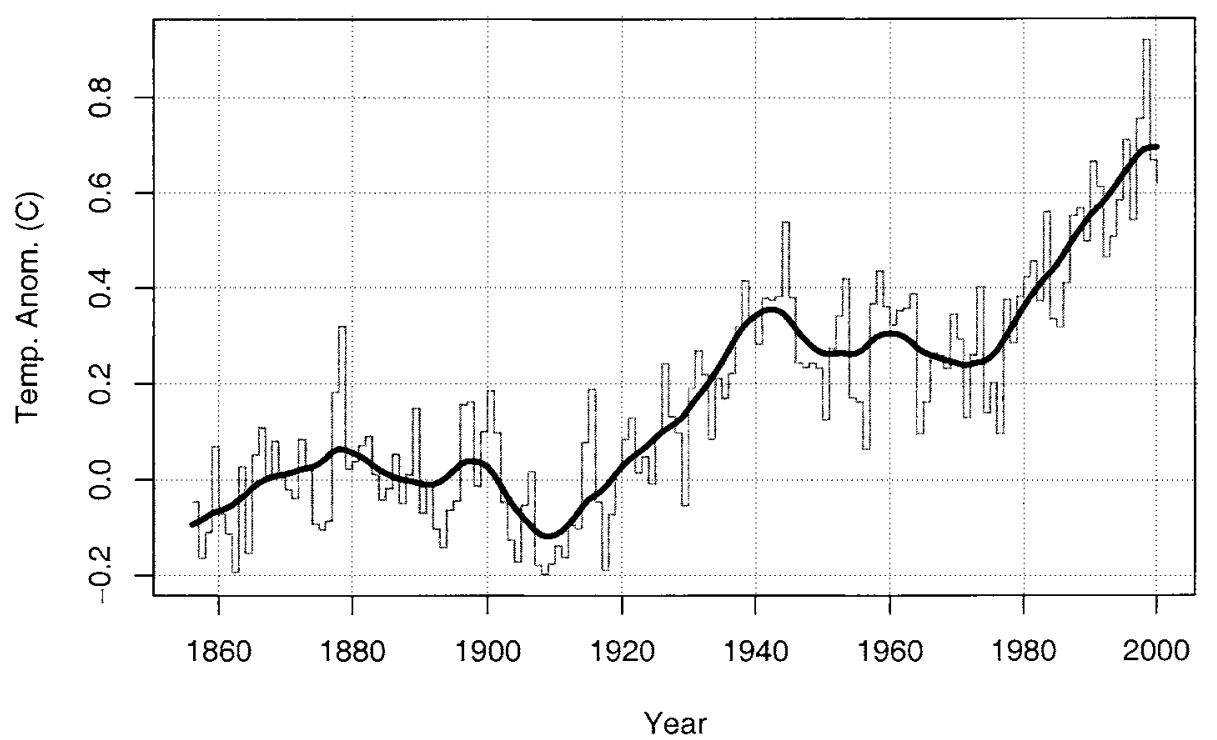

Figure 3. Annual global average surface temperature anomalies (C) with respect to the $1860-1900$ average. Data is from P. Jones, UEA (downloaded from http://www.cru.uea.ac.uk/cru/data/ temperature/).

the warming experienced from 1870 to 2000 (be it from natural, solar, or volcanic variability, or anthropogenic forcing) had already happened by 1970 . Therefore, we proceed with estimating $\triangle \mathrm{HC}$ from the difference between T averaged over 19951997 and Levitus climatology, with the caveat that this may introduce an error by underestimating the strength of the ocean heating by up to one-third. 


\subsection{EVALUATING THE ASSIMILATED DATA}

Approximating $\mathrm{HC}_{\text {model }}$ as in Equation (3) is not guaranteed to eliminate the problem of model temperature drift. Although the anomaly coupling method mandates that the model's climatological heat transports will be in balance, there is no such assurance for the anomalies. This will now be addressed.

The degree of similarity between the observed and model the $\Delta \mathrm{HC}$ fields can be evaluated by using the projection, $\mathrm{P}$, defined as

$$
\mathrm{P}=\frac{d \cdot p}{p \cdot p}
$$

where $d(\mathbf{x})$ is the data and $p(\mathbf{x})$ is a pattern of interest. The projection is closely related to the pattern correlation, but has a normalization that preserves information on the relative strength of $d$ and $p$ as well as their geographical similarity. So, for example, if $d$ looks exactly like $p$ (in both pattern and strength) then $\mathrm{P}=1$; if $d$ looks geographically similar to $p$ but is twice as strong, $\mathrm{P}=2$; and so on.

The target pattern $p$ used for the projection was the model's HC anomaly field below $250 \mathrm{~m}$, averaged over three ensemble members of the coupled model's business as usual (BAU) runs, and averaged over years 2090 to 2099. Only results below $250 \mathrm{~m}$ were considered to reduce the influence of interannual and interdecadal variability, which are strongest in the upper $250 \mathrm{~m}$ of the water column and not of direct interest in this project. The results of the projection are shown in Figure 4. The projection is calculated for each decade of the three BAU runs from the 2000s to the 2090s as well as for five historical runs (covering the 1870s to the 1990 s). Note that $\mathrm{P} \approx 1$ for each of the BAU runs by year 2100 , in accord with how the target pattern was formed. Figure 4 shows that by year 2000, the ocean has experienced $\sim 17 \%$ of the warming that will be accomplished by 2100 .

Also illustrated in Figure 4 (circles) are the results from projecting the observed $\mathrm{HC}$ anomaly fields onto the target pattern, by year. (Retaining temperatures only below 250 m prevents the strong El Niño year of 1997 from showing up as an anomalous data point.) It can be seen that the assimilation results are in surprisingly good agreement with the model results, although on the low side if averaged over all the years (this is in accord with the estimate above that the assimilated results may be up to $\sim 30 \%$ too low since the anomalies are not with respect to preindustrial conditions). Figure 4 motivates using the average T, S anomaly fields of the last three years of the assimilation run as the proper anomaly fields to add to the model climatology in forming the initial condition, since the projection values indicate that the assimilated fields have about the proper pattern of temperature anomalies, in about the proper strength, as compared to the model. This agreement with the model will result in minimal model drift.

The actual warming patterns (i.e., temperature anomaly below $250 \mathrm{~m}$ ) for the assimilated data in year 1997 and the model averaged over the 2090s are shown in Figure 5. The data have been spatially filtered to retain features gyre-scale and 


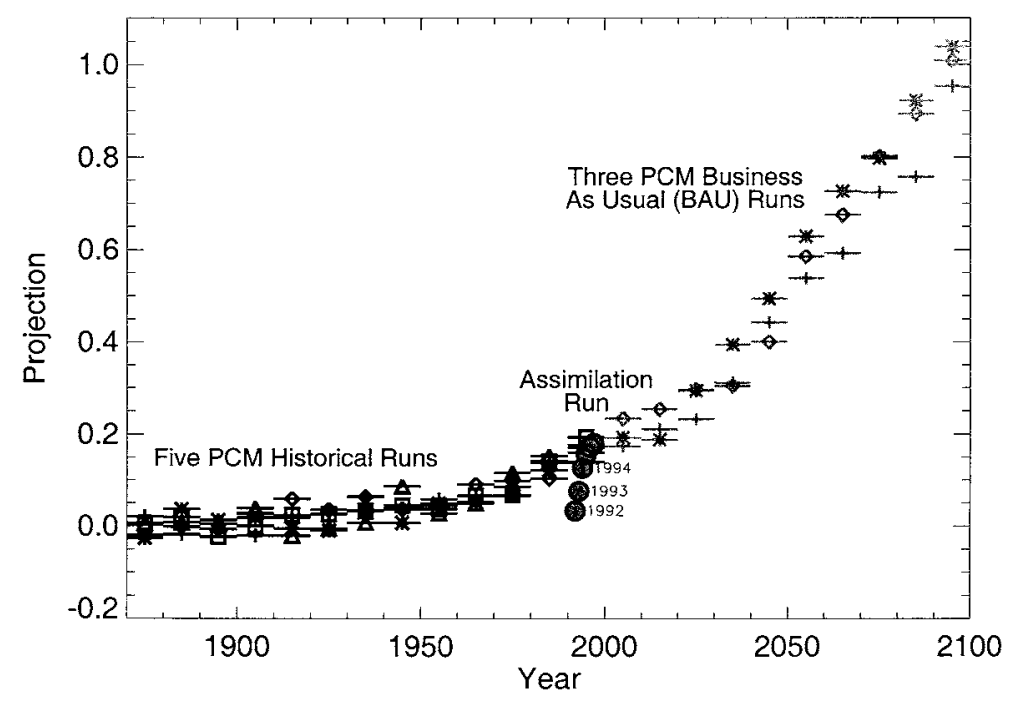

Figure 4. Projection of the model's ocean warming pattern (below 250 meters) in year 2100 onto the five model historical runs and three model business as usual (BAU) runs. The historical and BAU results are averaged by decade, as indicated by the horizontal bars. Also shown (circles) are the projections of the assimilated data onto the same target pattern; the first three years of the assimilation run are labeled by year.

larger, as we do not expect the model to capture the details of smaller oceanic features. The PCM experiences most of the warming in the North Atlantic and along the Antarctic circumpolar current (ACC); there is a relative minimum of warming in the central North Pacific. The assimilated data also has most of its warming in the North Atlantic (but farther northeast than in PCM) and the ACC; a band of smaller values is seen in the Pacific, as in PCM, but also extends into the southeast Pacific. The pattern correlation between the two fields is 0.56 , which is significant at the $95 \%$ level (based on the 12 degrees of freedom left after the spatial filtering). Note that the PCM field is smoother at least partly because of the greater averaging done (across 10 years and 3 ensemble members). This averaging is desirable, as it reduces high frequency variability not of interest here, but is not possible with the short, unique realization of the assimilated data set.

\subsection{FINAL MODEL DRIFT}

The coupled model was spun up for 5 years with the interior ocean $\mathrm{T}$ and $\mathrm{S}$ fields relaxed strongly (30-day time constant) to the initial conditions described above (i.e., anomalous ocean $\mathrm{T}$ and $\mathrm{S}$ fields obtained from the assimilated data set added to the coupled model's T and S climatology). This allowed the ocean velocity fields and atmosphere to come into equilibrium with the imposed $\mathrm{T}$ and $\mathrm{S}$ fields. The degree of drift after this still needs to be tested, because of the various approximations and inferences outlined above. It should be understood that there is no guarantee 

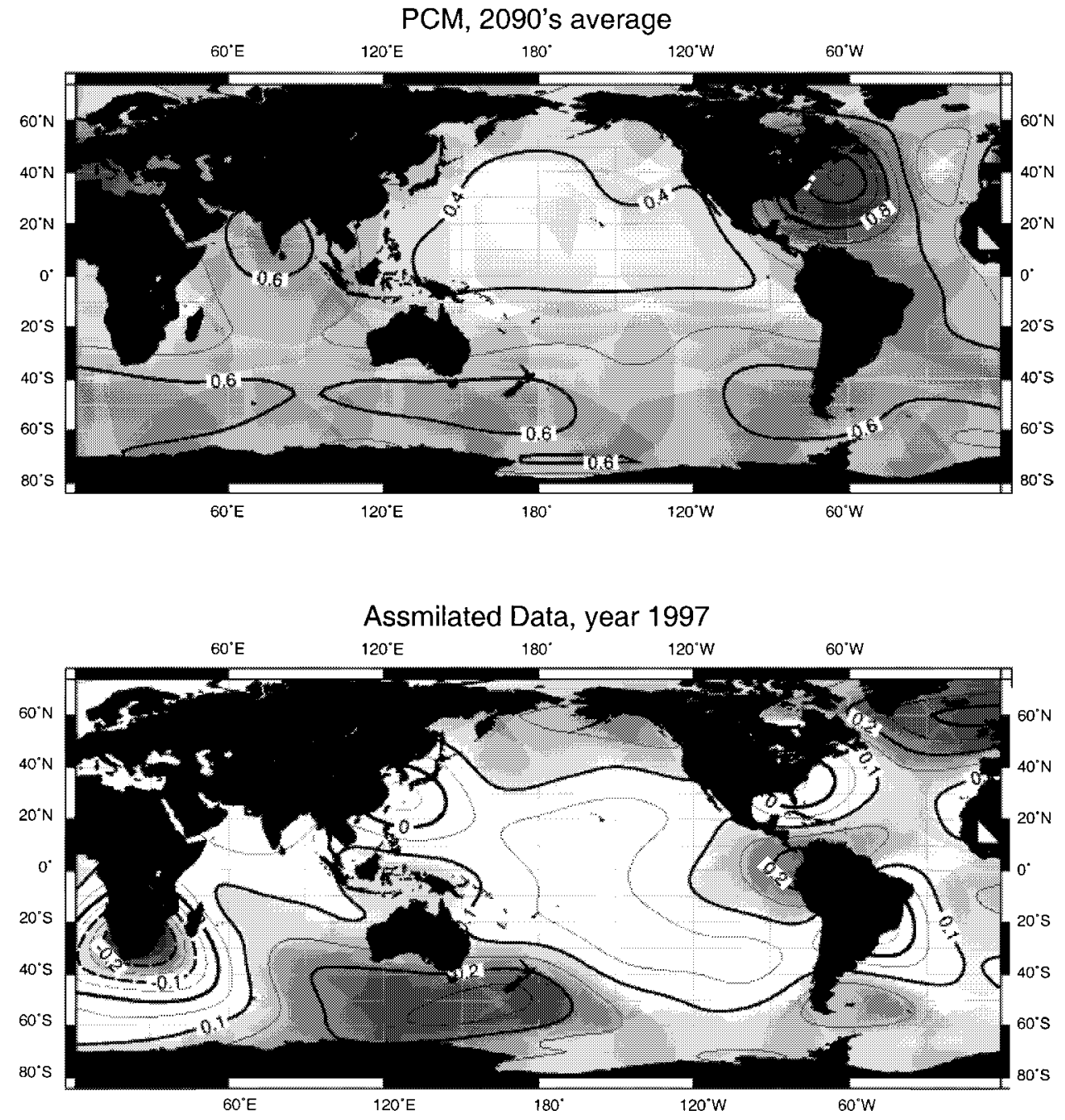

Figure 5. Temperature anomaly (C) below $250 \mathrm{~m}$. Top: model field, decade of the 2090s. Bottom: assimilated data field, year 1997.

that the drift will be small; the initialization technique merely attempts to match the observed initial condition to the model's expectations in a consistent way.

The final model drift was tested using a 50-year control run with the initial conditions noted above but anthropogenic forcing held fixed at 1995 values. The results are shown in Figure 1. The heavy solid line is the global average surface temperature for the control run with assimilated initial conditions but fixed anthropogenic forcing. Also shown is the ensemble average global surface temperature for the five BAU runs (light line with circles), along with $+/-2$ standard deviations (dotted lines). The temperature drift in the control run is about $0.2 \mathrm{~K}$ in 50 years. 
This compares favorably to the forced response of $1.0 \mathrm{~K}$ over 50 years, as estimated from the BAU runs. Thus, the assimilation technique reduces the problem of drift to the point where it is no more than 1 part in 5 of the forced signal. Additionally, by year 2050 the distribution of values found in the BAU runs is well separated from the variability found in the control run.

\section{Initializing to a Neutral ENSO State}

To initialize the model to a neutral ENSO state despite including 1997 (the largest El Niño on record) in the initialization time period, a vertical weighting scheme was applied to the assimilated temperature anomalies before they were added to the model climatology. The objective of the scheme is to preserve the heat content anomaly associated with the anthropogenic warming, but damp the heat content anomalies associated with ENSO and other interannual to decadal variability. Accordingly, temperature anomalies below $250 \mathrm{~m}$ were not altered (to preserve the anthropogenic warming signal accumulated from 1870 to 1997), while values above $250 \mathrm{~m}$ were ramped to zero at the surface. The depth at which the weight was 0.5 was $90 \mathrm{~m}$.

The effect this has on the anomalous HC due to anthropogenic forcing and ENSO can be estimated. Applying the vertical weighting profile to the model's anthropogenic signal resulted in $82 \%$ of the heat content anomaly being retained. For the ENSO signal (obtained as the leading EOF of the White 1995 threedimensional temperature XBT-based data set, high-pass filtered to retain periods shorter than 7 yrs/cycle) only $49 \%$ of the heat content signal was retained. While not perfect, this scheme gives a reasonable compromise between removing the ENSO signal, retaining the anthropogenic signal, and simplicity.

It should be noted that initializing the model to near-neutral ENSO conditions in the ocean does not prevent the subsequent development of any non-linear interactions between anthropogenic forcing and ENSO (or other interannual to decadal variability). This is important, as is well known that seasonal rainfall and temperatures over the western U.S. are affected by ENSO (e.g., Cayan et al., 1999) and the north Pacific oscillation (NPO; e.g., Latif and Barnett, 1996). These effects will be present in the pilot-ACPI predictions, and it is entirely possible that one manifestation of anthropogenic forcing will be a change in the frequency or amplitude of ENSO (e.g., Meehl and Washington, 1996; Cane et al., 1997; Timmermann et al., 1999).

\section{Assimilated versus Spun-up Initial Conditions}

Does using the assimilated initial conditions give different results than simply spinning the model up from pre-industrial conditions? This can be evaluated by 
comparing with the existing set of standard PCM runs that start with pre-industrial conditions and integrate forward past year 2050 with BAU forcing. Since the pilot-ACPI ensembles have only three members, we evaluated this with the nonparametric statistical technique of Preisendorfer and Barnett (1983), which was constructed specifically for problems with a small number of ensemble members. This technique outputs two measures: SITES, which evaluates the similarity of the mean patterns (e.g., of the surface temperature fields or snow cover), and SPREAD, which evaluates the similarity of the variability. The end result is a score showing how likely the grouping of ensemble members into data sets is. If the grouping appears to be random, then it can be inferred (in our particular case) that there is no systematic difference between runs with assimilated or spun-up initial conditions. Other possible outcomes are that the ensembles are unusually different, which would suggest that the assimilation had a significant effect, or that the ensembles are improbably similar, which would suggest that the initialization technique failed to modify the initial T, S fields in the first place.

Figure 6 shows the SITES statistic comparing the pilot ACPI runs to the standard PCM BAU runs over North America. (For plotting purposes the score has been transformed with an inverse error function so that the tails of the distribution, where the confidence limits are located, can be more clearly seen.) The varying initial condition made no difference, even at short time lapses, to any variable. For completeness, we also checked the northern hemisphere and global fields, and the SPRED (intra-ensemble variance) statistic as well as the SITES statistic. Further examples are given in Pierce et al. (2002). In no case did the initial conditions make any difference, except to the accumulated snow depth field atop Antarctica, which was inadvertently not reset to a consistent value at the start of all the runs (this is irrelevant to the ocean initialization procedure we are examining).

It is worth considering this result in light of Section 4, which showed that the heat content anomaly obtained from the PCM spinup runs is similar in pattern and magnitude to the assimilated initial conditions (Figure 4). It is likely that the null effect of assimilated initial conditions is another reflection of the similarity between PCM and the assimilated data. If so, then a model less like the observations might benefit substantially by using the assimilated initial conditions. In any event, the correct conclusion is not that that the details of the 1995 climate make no difference to later years, but rather that substituting the assimilated initial conditions into PCM in place of the spinup conditions makes no difference to later climate. It cannot be ruled out that this is simply because PCM simulates the initial condition rather well, an idea supported by the heat content analysis of Barnett et al. (2001).

\section{Summary and Conclusions}

This note described a new technique used to initialize a coupled climate model with observed initial conditions (taken from an assimilation run), and evaluated the 
TS
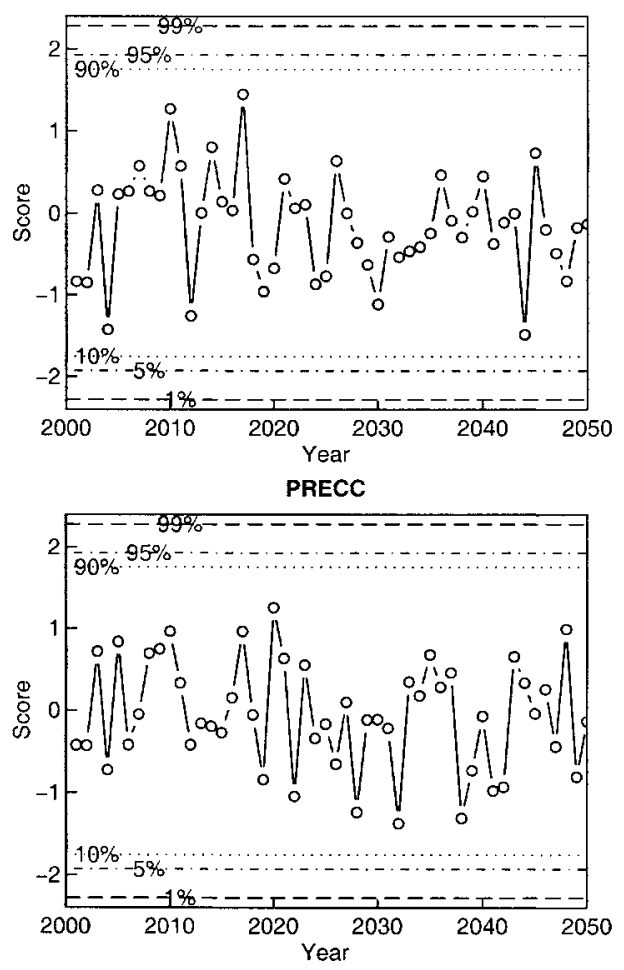

PSL

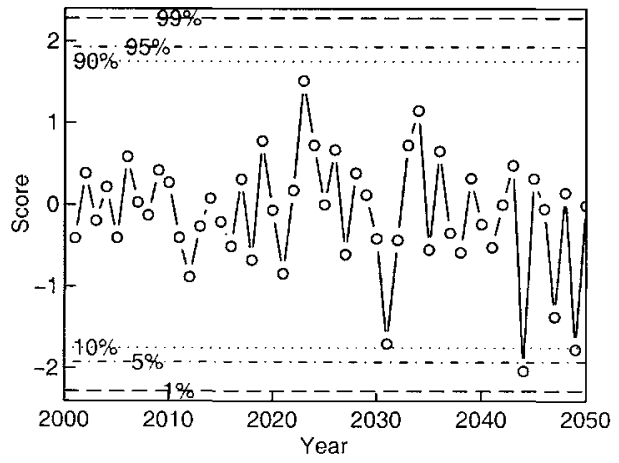

CLDTOT
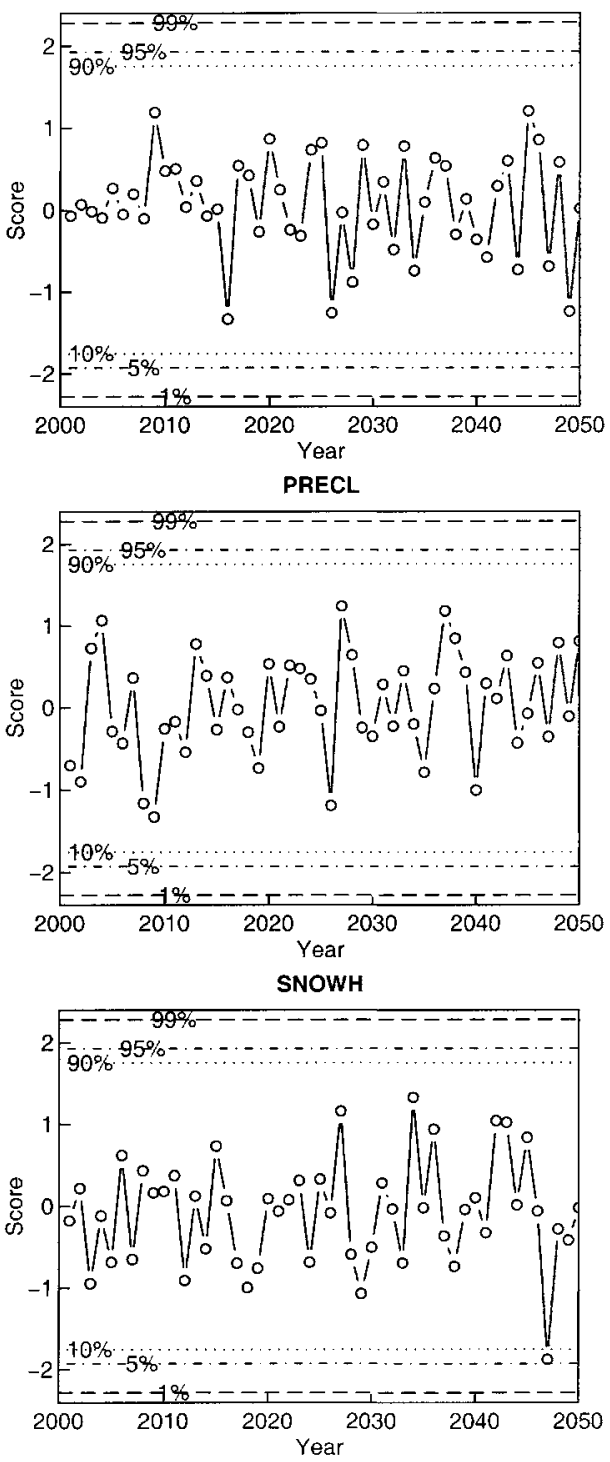

Figure 6. SITES statistic comparing the pilot ACPI run to the standard PCM BAU runs. Variables compared are: TS = surface temperature; CLDTOT = cloud fraction; $\mathrm{PRECC}=$ convective precipitation; PRECL = large scale precipitation; $\mathrm{PSL}=$ sea level pressure; $\mathrm{SNOWH}=$ snow depth. Values over North America were included. See text for further details. 
impact this had on subsequent climate projections. Observed heat content anomalies were inserted into the climate model by adding them to the coupled climate model's climatology. It was shown that this technique worked because the model and observed anomalous temperature fields were similar in both pattern and magnitude. Any potential problems with including 1997 (an exceptionally strong El Niño year) in the initial condition were mitigated by ramping temperature anomalies to zero near the surface, so that the main part of the anthropogenic heat content signal was retained while the ENSO signal was damped towards neutral conditions.

Comparing climate projections using the assimilated initial conditions to those made by spinning up from pre-industrial conditions, it was found that the assimilated initial conditions made no systematic difference. This is likely another reflection of the similarity between the model and observed patterns of anomalous temperature; switching from the spinup to the assimilated conditions is a relatively small change. This might be different in a model that had a worse representation of the anomalous ocean heat content in the late 20th century.

This work leaves unanswered why the model spinup and assimilated initial conditions are so similar. It might be that both the model and the assimilation are skillful in predicting this field, in which case their similarity is testament to the good quality of the results. It could also be because both are based on modern general circulation models (albeit different ones), which might have similar systematic errors. Independent analysis of model versus observed heat content fields (Barnett et al., 2001; Levitus et al., 2001) suggest that models can, in fact, skillfully capture this field. However, a detailed comparison of the assimilated versus observed data remains to be done.

\section{Acknowledgements}

This work was supported by the Department of Energy under grant DE-FG0398ER62505. The assimilated ocean data fields are a contribution of the Consortium for Estimating the Circulation and Climate of the Ocean (ECCO), funded by the National Oceanographic Partnership Program. Most of the computations for the work described here were done under the auspices of the National Partnership for Advanced Computer Infrastructure (NPACI) at the San Diego Supercomputer Center, with the help of Peter Arzberger and Giridhar Chukkpalli. The rest were done at Oak Ridge National Laboratory, and we acknowledge the Center for Computational Sciences-Climate and Carbon Research (CCS-CCR) at Oak Ridge for computational resources used in support of this project. John Drake's role in securing and expediting those resources under the auspices of the Climate Change Prediction Program (CCPP) is gratefully acknowledged. 


\section{References}

Adcroft, A., Hill, C., and Marshall, J.: 1997, 'Representation of Topography by Shaved Cells in a Height Coordinate Ocean Model', Mon. Wea. Rev. 125, 2293-315.

Barnett, T. P., Malone, R., Pennell, W., Stammer, D., Semtner, A., and Washington, W.: 2004, 'The Effects of Climate Change on Water Resources in the West: Introduction and Overview', Clim. Change 62, 1-11.

Barnett, T. P., Pierce, D. W., and Schnur, R.: 2001, 'Detection of Anthropogenic Climate Change in the World's Oceans', Science 292, 270-274.

Cane, M. A., Clement, A. C., Kaplan, A., Kushnir, Y., Pozdnyakov, D., Seager, R., Zebiak, S. E., and Murtugudde, R.: 1997, 'Twentieth-Century Sea Surface Temperature Trends', Science 275, 957-960.

Cayan, D. R., Redmond, K. T., and Riddle, L. G.: 1999, 'ENSO and Hydrologic Extremes in the Western United States', J. Climate 12, 2881-2893.

Dai, A., Washington, W. M., Meehl, G. A., Bettge, T. W., and Strand, W. G.: 2004, 'The ACPI Climate Change Simulations', Clim. Change 62, 29-43.

Dukowicz, J. K. and Smith, R. D.: 1994, 'Implicit Free-Surface Method for the Bryan-Cox-Semtner Ocean Model', J. Geophys. Res. 99, 7991-8014.

Fu, L.-L., Christensen, E. J., Yamarone, C. A. Jr., Lefebvre, M., Menard, Y., Dorrer, M., and Escudier, P.: 1994, 'TOPEX/POSEIDON Mission Overview', J. Geophys. Res. 99, 24369-2481.

Hasselmann, K., Sausen, R., Maier-Reimer, E., and Voss, R.: 1993, 'On the Cold Start Problem in Transient Simulations with Coupled Atmosphere-Ocean Models', Clim. Dyn. 9, 53-61.

Hunke, E. C. and Dukowicz, J. K.: 1997, 'An Elastic-Viscous-Plastic Model for Sea Ice Dynamics', J. Phys. Oceanog. 27, 1849-1867.

IPCC: 1994, 'Climate Change 1994: Radiative Forcing of Climate Change and an Evaluation of the IPCC IS92 Emission Scenarios', in Houghton, J. T., Meira Filho, L. G., Bruce, J., Lee, H., Callander, B. A., Haites, E., Harris, N., and Maskell, K. (eds.), Cambridge University Press, 339 pp.

Jones, P. D., New, M., Parker, D. E., Martin, S., and Rigor, I. G.: 1999, 'Surface Air Temperature and its Changes over the Past 150 Years', Rev. of Geophysics 37, 173-199.

Kalnay, E, Kanamitsu, M., Kistler, R., Collins, W., Deaven, D., Gandin, L., Iredell, M., Saha, S., White, C., Woollen, J., Zhu, Y., Chelliah, M., Ebisuzaki, W., Higgins, W., Janowiak, J., Mo, K. C., Ropelewski, C., Wang, J., Leetmaa, A., Reynolds, R., Jenne, P., and Joseph, D.: 1996, 'The NCEP/NCAR 40-Year Reanalysis Project', Bull. Amer. Meteorol. Soc. 77, 437-471.

Kiehl, J. T., Hack, J. J., Bonan, G. B., Boville, B. A., Williamson, D. J., and Rasch, P. J.: 1998, 'The National Center for Atmospheric Research Community Climate Model: CCM3', J. Climate 11, $1131-1149$.

Latif, M. and Barnett, T. P.: 1996, 'Decadal Climate Variability over the North Pacific and North America: Dynamics and Predictability', J. Climate 9, 2407-2423.

Levitus, S.: 1994, World Ocean Atlas 1994, U.S. Dept. of Commerce, National Oceanic and Atmospheric Administration, $552 \mathrm{pp}$.

Levitus, S., Antonov, J. I., and Boyer, T. P.: 2000, 'Warming of the World Ocean', Science 287, 2225-2229.

Levitus, S., Antonov, J. I., Delworth Julian Wang, Dixon T. L., and Broccoli, K. W., A. J.: 2001, 'Anthropogenic Warming of Earth's Climate System', Science 292, 267-270.

Marshall, J., Adcroft, A., Hill, C., Perelman, L., and Heisey, C.: 1997b, 'A Finite-Volume, Incompressible Navier Stokes Model for Studies of the Ocean on Parallel Computers', J. Geophys. Res. 102, 5753-5766.

Marshall, J., Hill, C., Perelman, L., and Adcroft, A.: 1997a, 'Hydrostatic, Quasi-Hydrostatic, and Nonhydrostatic Ocean Modeling', J. Geophys. Res. 102, 5733-5752. 
Meehl, G. A. and Washington, W. M.: 1996, 'El Nino-Like Climate Change in a Model with Increased Atmospheric $\mathrm{CO}_{2}$ Concentrations', Nature 382, 56-60.

Meehl, G. A., Washington, W. M., Wigley, T. M. L., Arblaster, J. M., and Dai, A.: 2002, 'Solar and Greenhouse Gas Forcing and Climate Response in the 20th Century', J. Climate, in press.

Pierce, D. W., Barnett, T. P., Tokmakian, R., Semtner, A., Maltrud, M., Lysne, J., and Craig, A.: 2002, 'The ACPI Demonstration Project, Element 1: Initializing the Coupled Model from Observed Conditions', Scripps Institution of Oceanography Reference Series No. 2002-5, 30 pp.

Preisendorfer, R. W. and Barnett, T. P.: 1983, 'Numerical Model-Reality Intercomparison Tests Using Small-Sample Statistics', J. Atmos. Sci. 40, 1884-1896.

Schneider, E. K.: 1996, 'Flux Correction and the Simulation of Changing Climate', Annales Geophysicae 14, 336-341.

Smith, R. D., Dukowicz, J. K., and Malone, R. C.: 1992, 'Parallel Ocean General Circulation Modeling', Physica D 60, 38-61.

Stammer, D., Wunsch, C., Giering, R., Eckert, C., Heimbach, P., Marotzke, J., Adcroft, A., Hill, C. N., and Marshall, J.: 2002, 'Global Ocean Circulation during 1992-1997, Estimated from Ocean Observations and a General Circulation Model', J. Geophys. Res., 10.1029/2001JC000888.

Stammer, D., Wunsch, C., Giering, R., Zhang, Q., Marotzke, J., Marshall, J., and Hill, C.: 1997, The Global Ocean Circulation Estimated from TOPEX/POSEIDON Altimetry and the MIT General Circulation Model, Technical Report No. 49, Available from MIT Center for Global Change Science, Cambridge, MA 02139 U.S.

Timmermann, A., Oberhuber, J., Bacher, A., Esch, M., Latif, M., and Roeckner, E.: 1999, 'Increased El Nino Frequency in a Climate Model Forced by Future Greenhouse Warming', Nature 398, 694-697.

Washington, W. M., Weatherly, J. W., Meehl, G. A., Semtner, A. J., Bettge, T. W., Craig, A. P., Strand, W. G., Arblaster, J., Wayland, V. B., James, R., and Zhang, Y.: 2000, 'Parallel Climate Model (PCM) Control and Transient Simulations', Clim. Dyn. 16, 755-774.

White, W. B.: 1995, 'Network Design of a Global Observing System for Gyre-Scale upper Ocean Temperature Variability', Prog. Oceanogr. 36, 169-217.

Zhang, J. and Hibler, W. D.: 1997, 'On an Efficient Numerical Method for Modeling Sea Icedynamics', J. Geophys. Res. 102, 8691-8702.

(Received 9 July 2002; in revised form 8 April 2003) 